\title{
Design of mobile phones for older adults: An empirical analysis of design guidelines and
} checklists for feature phones and smartphones

\author{
Andraž Petrovčič,${ }^{\mathrm{a}, *}$ Sakari Taipale, ${ }^{\mathrm{b}}$ Ajda Rogelj, ${ }^{\mathrm{c}}$ and Vesna Dolničar ${ }^{\mathrm{a}}$
}

${ }^{a}$ Faculty of Social Sciences, University of Ljubljana, Kardeljeva ploščad 5, 1000 Ljubljana, Slovenia

${ }^{b}$ Department of Social Sciences and Philosophy, University of Jyväskylä, Keskussairaalantie 2, P.O. Box 35, 40014 Jyväskylä, Finland

${ }^{\mathrm{c}}$ Institute of Public Health of the Republic of Slovenia, Trubarjeva 2, 1000 Ljubljana, Slovenia

* Corresponding author: andraz.petrovcic@fdv.uni-lj.si. Telephone: +386 15805 200. Fax: +38615805101.

The present post-print may not replicate the final version published in the Taylor \& Francis journal. It is not the copy of record and may differ from the final version.

This article has been accepted for publication in International Journal of Human-Computer Interaction published by Taylor \& Francis. The publisher's version of this article is available at: https://www.tandfonline.com/doi/full/10.1080/10447318.2017.1345142

Suggested citation Petrovčič, A., Taipale, S., Rogelj, A. and Dolničar, V. (2018). Design of mobile phones for older Adults: an empirical analysis of design guidelines and checklists for feature phones and smartphones. International Journal of Human-Computer Interaction, 34(3), 251-264, DOI: 10.1080/10447318.2017.1345142 


\title{
Design of mobile phones for older adults: An empirical analysis of design guidelines and checklists for feature phones and smartphones
}

\begin{abstract}
:
Design guidelines and checklists are suggested as a useful tool in the development and evaluation of interface design of mobile phones for older adults. Given the intense evolution of mobile phone design, understanding how the design guidelines and checklists have taken into account the advances in mobile phone usability for older adults is important for their correct application and future development. Thus, this study explores the usability dimensions of mobile phone design for older adults and the related changes in terms of time and the type of device (feature phones vs. smartphones) based on an expert coding of the eight mobile phone design guidelines and checklists for older adults published between 2006 and 2014. The results of the expert coding show that design guidelines and checklists most frequently deal with visual and haptic issues (e.g., high contrast, button type, and button size), whilst they hardly ever address various elements of textual interface (e.g., ease of text entry, a button's feedback, and font type). Over time, the design guidelines and checklists have become more complex in terms of the average number of included usability categories and dimensions. For smartphones, the guidelines, on average, put more emphasis on the screen, touchscreen, text, and exterior related issues, whereas the design guidelines for feature phones stress the usability of the keypad and menus. Besides revealing potential usability dimensions that could be further expanded in the guidelines, this study also highlights the need for research that would empirically validate the design guidelines and checklists in the future.
\end{abstract}

Keywords: checklists, guidelines, design, heuristic analysis, mobile phone, older adults, usability 


\section{Introduction}

Mobile phones are becoming an important aspect of older adults' everyday lives. They are no longer used only for voice and text communication; smartphones can also be utilized as assistive technologies via the applications installed on them to monitor older adults' health, to prevent accidents and critical situations, and/or to access knowledge and learning resources (Joe \& Demiris, 2013; Plaza, Martín, Martin, \& Medrano, 2011). Recent figures from the US and UK reveal that the percentage of older adults who use a smartphone ${ }^{1}$ has considerably increased in recent years. For instance, the proportion of smartphone users aged 65 and above rose from $18 \%$ to $27 \%$ in the US between 2013 and 2015 (Smith, 2013, 2015), whereas the change between 2013 and 2014 in the UK was 6 percentage points - from $20 \%$ to $26 \%$ - for those aged 65-74 years, and 2 percentage points - from 5\% to $7 \%$ - for those aged 75 years and older (Ofcom, 2015).

Irrespective of whether older adults are seen through the lens of chronological age or functional age, they face age-related changes (e.g., in their hearing, vision, motor skills, and/or cognitive skills) that may affect their use of mobile phones. As part of the research on the cognitive, perceptual, and motoric limitations associated with the aging process (Fisk, Rogers, Charness, Czaja, \& Sharit, 2009), many scholars have investigated various human factors and interaction elements in mobile phone design, including ergonomics, device- and screen-based

\footnotetext{
${ }^{1}$ Even though there is no full agreement on the definition (and differences) between a feature phone and a smartphone, we follow Callegaro, Lozar Manfreda, and Vehovar (2015), who suggested that a feature phone has fewer functions than a smartphone. While feature phones may allow web browsing, they provide no or limited support for Wi-Fi Internet access, touchscreen capabilities, and/or the downloading of applications. Accordingly, a smartphone can be described as a device that offers advanced functions and services that generally require a touchscreen and progressive computing capabilities, including an advanced mobile operating system that supports the downloading and running of applications (Callegaro et al., 2015). We use the term mobile phone when referring to both feature phones and smartphones.
} 
controllers, interface structure and organization, navigation, and so on. In fact, studies are increasingly being published in the field of human-computer interaction (HCI), testing various devices and interface design solutions for mobile phones. Consequently, there have also been attempts to summarize the results into design checklists or guidelines that can be used during inspection to evaluate the usability of mobile phone devices and services for older adults (see Section 3.2). Design guidelines and checklists in combination with heuristic evaluation represent a valuable tool for evaluating a product design, since this provides a relatively inexpensive, quick, low resource-intensive tool (Dumas \& Salzman, 2006). While heuristic evaluation has proven to be a comprehensive and efficient method for inspecting the usability of mobile phones (Ji, Park, Lee, \& Yun, 2006), in age-friendly design for older adults, this aspect seems to be even more important, since the inclusion of older adults in empirical and experimental HCI research has been recognized as challenging (Dickinson, Arnott, \& Prior, 2007). Notably, older adults generally require an adjusted approach to investigate their needs and maximize the value of the collected information. Dickson et al. (2007) explained that these adjustments relate to recruitment, retention, and work with older adults as three central stages of the HCI research process. They also suggested that enacting the appropriate changes often demands additional organizational, technical, and managerial resources that might not be available to researchers.

Using a heuristic evaluation that is based on expert review might alleviate or even allow for overcoming many of these analytical and procedural impediments (Fisk et al., 2009). Such advantages have also been recognized by scholars and practitioners dealing with the agefriendly usability and design of mobile phones, who developed the first design guidelines and checklists aimed at older adults (Pattison \& Stedmon, 2006). However, the rapid technological development of mobile phones has provided a wide array of device and interface design solutions, driving usability specialists and scholars to adapt the set of heuristics to obtain the 
required levels of relevance and validity (Wangenheim et al., 2016). Notably, the development of mobile phones has introduced design solutions that are related to many usability dimensions. For example, the development of mobile phone design brought about innovations in terms of device shape and size, display size and resolution, position of buttons, keypad shape and size, structure and complexity of menus, variants of interaction styles (Cecere, Corrocher, \& Battaglia, 2015). Very recently, many mobile phone user interface (UI) elements were further affected by touchscreen-based smartphones with gestural interfaces (Stössel, Wandke, \& Blessing, 2010). This led scholars to reconsider some of the prior findings and usability recommendations and adapt the design guidelines and checklists for feature phones (Zhou, Rau, \& Salvendy, 2013, 2012), which have also been scarcely integrated into mobile operating system (OS)-specific design principles and style guides compiled by the mobile industry (Wangenheim et al., 2016).

Exploring the evolvement and adaptation of guidelines and checklists for the agefriendly design of mobile phones from a time-wise and device-wise perspective could give us a more nuanced understanding of how usability research has followed the innovations in mobile phone design and scholarly inquiry in the sense of adjusting existing and/or proposing new design requirements. In particular, it seems relevant to consider whether smartphones with gestural interfaces have influenced design guidelines and checklists in terms of introducing heuristics related to new usability dimensions and/or of changing the existing ones. Moreover, such insights based on scholarly inquiry can also be relevant because they can show us the eventual heuristics and usability dimensions that need to be revised and/or expanded in the guidelines. This aspect seems crucial due to the large variation in the design characteristics for older adults and the corresponding difficulty that practitioners face in identifying a set of validated UI design criteria that would be applicable to the general population of older adults (Butlewski, Tytyk, Wróbel, \& Miedziarek, 2014). Surprisingly, even though the first guidelines 
for the age-friendly design of feature phones were published more than 10 years ago (Pattison $\&$ Stedmon, 2006), we are not familiar with any attempt to more closely scrutinize their contents and evolution.

It is against this backdrop that we proposed the twofold aim of this study. On the one hand, the study is aimed at exploring the usability dimensions of age-friendly mobile phone design for older adults that have been included in the published design guidelines and checklists for mobile phones. On the other hand, it is aimed at investigating the changes in the usability dimensions associated with the age-friendly design of mobile phones in the literature in recent years. In particular, we seek to explore whether there were any changes in the presence of different usability dimensions in the heuristics over the years and whether the identified changes could be associated with the distinction between feature phones and smartphones.

In the following section, we provide a literature review of studies on UI design for older adults focused on the interaction design elements of feature phones and smartphones that could have informed the heretofore published design guidelines and checklists used for heuristic evaluation. In Section 3, we describe the procedures and methods used in the empirical part of this study that were based on an expert coding of eight sets of design guidelines and checklists published previously. In Section 4, the empirical results of the expert coding are presented. Section 5 provides a discussion of the empirical findings, lays out the limitations of this study, and provides the final conclusions and implications of the study.

\section{Literature Review}

This section presents an overview of the literature, separating the prior research findings on the role of device-based and screen-based controllers (Section 2.1.) and menu and navigation interaction elements (Section 2.2) in the feature phone UI design from interaction design elements that are particular to touchscreen-based smartphones for older adults (Section 2.3). Studying the adaptations and additions in the interaction elements over time that resulted in a 
thorough overview of the development of the field enabled a more informed and evidencebased insight into the usability dimensions and categories of the design of mobile phones for older adults. The literature overview, thus, served as a knowledge base for a systematic approach to the development of the operative coding scheme for design guidelines and checklists used in the empirical analysis in Section 3.

\section{$2.1 \quad$ Device-based and screen-based controllers}

Table 1 summarizes the previous results on the input and output interaction elements of a feature phone from the perspective of the mobile phone UI design for older adults. Buttons are considered to be of extreme importance, with older adults preferring large and raised keypad buttons with clear feedback. The latter can be visual (e.g., highlighting or the visibility of an hourglass while loading), auditory (click), and/or tactile. The buttons should not be too sensitive to avoid accidental pressing, since older adults often find themselves pressing the wrong buttons (Kim et al., 2007). Moreover, sufficient space between buttons, the location of the keypad at the bottom of the interface, so that the typing hand does not hide the screen, and easy-tounderstand buttons facilitate mobile use among older adults. Studies also suggest that scroll buttons should be avoided or at least minimized.

Regarding the display of a feature phone, large, high contrast screens with options for zooming in and increasing font size improve the readability of the screen. The screen-dimming time should be prolonged to ensure that older adults have enough time for cognitive processing and executing the required operations (Hassan \& Nasir, 2008). Graphics should promote better understanding and recognition with the use of simple and meaningful icons designed in line with the mental models of older adults, who also dislike decoration and animation. Moreover, the literature suggests applying conservative colors and using a high screen contrast between the foreground and background. 
Form factors, such as size, shape, weight, and style, as well as the layout and position of the major ergonomic components, are important aspects of usability and ergonomics for older adults. The feature phone should be big enough to enable a comfortable grip, but also light enough for convenient carrying (Kim et al., 2007). Some studies indicate that older adults give preference to bar-shape feature phones (Wang, 2008), older women prefer flip feature phones (Kurniawan, 2008), and older adults generally dislike slide-out feature phones (Massimi, 2007). Lastly, integrating audio adjustments into the device is advisable (Boustani, 2010; Caprani, O'Connor, \& Gurrin, 2012; Kim et al., 2007), a wide range of volume levels should be provided to enable quality sound, and the device should be compatible with hearing aids.

[Insert Table 1 about here]

\subsection{Menu and navigation interaction elements}

As the features and services of feature phones expanded, the menu and navigation UI elements came to be characterized by increasing complexity. Thus, there is a requirement for adequate cognitive resources that can represent issues in the use of feature phones by older adults (Holzinger, Searle, \& Nischelwitzer, 2007; Irie, Matsunaga, \& Nagano, 2005; Mann et al., 2004; Pattison \& Stedmon, 2006; Ziefle, 2010; Ziefle \& Bay, 2005), whose cognitive performance slows down with age (Fisk et al., 2009; Haigh, 1993).

Table 2 summarizes previous results regarding the significant elements of menu and navigation interaction for older adults. First, studies suggest that older adults feel stress when the structure of the menu becomes deeper. Hence, menus should be simplified and flattened, and the nesting of features and available options should be avoided, as older adults require a longer time to think of what to select (Gao, Ebert, Chen, \& Ding, 2015; Kim et al., 2007; Lee, 2007; Mi, Cavuoto, Benson, Smith-Jackson, \& Nussbaum, 2014). As older adults' mental models are not always hierarchical, a one-level menu navigation may be easier to manage. Next, the complex menu structure causes older adults to experience disorientation in menu navigation, 
which is hampered by the small screen of a feature phone, which is typically not large enough to provide a full image of the menu but just a glimpse of a few icons at a time. Third, function naming plays a key role in the UI design for older adults, who need clues about what to do during menu navigation. Graphical symbols and buttons should ideally include labels and textual explanations, as this makes comprehension more straightforward. Self-explanatory naming facilitates memorizing icons names, their location within the menu, and the required paths for executing a specific task. Furthermore, function naming should be aimed at achieving maximal transparency and minimal ambiguity (e.g., avoidance of foreign expressions, abbreviations, and technical terms).

[Insert Table 2 about here]

\subsection{Interaction design of smartphones for older adults}

Smartphones have introduced new hardware and software solutions that can affect usability, putting in question some of the early findings in the field of mobile phone design for older users. Table 3 presents a summary of the findings related to the most important interaction elements that became relevant with the introduction of touchscreen-based smartphones. Touchscreens with gestural UI were suggested to minimize the usability issues of older adults related to impaired vision, reduced dexterity, and memory loss (Kobayashi et al., 2011). Moreover, they can alleviate the cognitive problems of older adults with indirect input (Stössel et al., 2010) and lessen the disorientation caused by hierarchical menus (Zhou et al., 2013, 2012). Generally, this is due to the much larger screen size and higher resolution display of a touchscreen-based smartphone (Boulos, Wheeler, Tavares, \& Jones, 2011; Gao \& Koronios, 2010; Lorenz \& Oppermann, 2009). Boulous et al. (2011) underlined that the use of smartphones could be very appropriate for older adults, as a touchscreen allows for building virtual buttons as large as needed, in contrast to the small buttons available on feature phones. Accordingly, the issues of font size and readability, plus the size and shape of the buttons, also 
seem to be less problematic with smartphones in terms of interface design (Armstrong, Nugent, Moore, \& Finlay, 2010).

Another issue relating to the screen properties of smartphones is the prolonged screendimming function. Smartphone sensors can detect when the smartphone is being held, so that the display lights stay on and the user can execute the intended tasks without interruption (Furuki \& Kikuchi, 2013). Moreover, Lee, Poliakoff, and Spence (2009) and Hwangbo, Yoon, Jin, Han, and Ji (2013) found that feedback can be significantly improved with a touchscreen. Their experimental data indicated that multimodal feedback with auditory and tactile (i.e., vibrating) signals via a touchscreen device results in enhanced performance and subjective benefits for older adults.

Significantly, there are aspects of age-friendly design that are not important with feature phones, but have become more important with smartphones. For instance, since most touchscreen-based phones only have a few (hardware) buttons, their target size and position on the screen can be an issue. The research of Leitao and Silva (2012) showed that the performance of older adults was optimal with a target size between $14 \mathrm{~mm}$ and $17.5 \mathrm{~mm}$, where large virtual buttons had a shorter reaction time than smaller ones (Zhou et al., 2012). Moreover, Hwangbo et al. (2013) confirmed that pointing performance increased when the target size increased and the spacing between targets widened, as well as when the targets were located in the upper right direction from the center point.

While touchscreens are well-suited for direct manipulation, even a very simple gesture (e.g., tap, press, or swipe) can create difficulties for older adults, who do not have a good sense for tapping on the screen (Furuki \& Kikuchi, 2013; Harada, Sato, Takagi, \& Asakawa, 2013; Motti, Vigouroux, \& Gorce, 2013). They experience problems with recognizing when a button or a target is pressed, which often results in (too) long taps and the pressing of wrong buttons. In relation to this, because of older adults' slow operation when tapping and executing specific 
tasks, they also encounter problems with text entry when using virtual keyboards (Motti et al., 2013; Zhou, Rau, \& Salvendy, 2014a; Zhou et al., 2012). Besides control over pressed keys, virtual keyboards demand good motoric and visual synchronization between button keys and the display response (Zhou et al., 2012). In general, older adults often need additional time to comprehend the movements needed for touchscreen operation and to differentiate between a tap, double tap, drag, flick and finch, or a multi-touch (Furuki \& Kikuchi, 2013; Motti et al., 2013; Zhou et al., 2014a). Furthermore, older adults often feel confused differentiating between the parts of the screen that can be, and should not be, tapped on (Harada et al., 2013; Zhou et al., 2012).

Lastly, Zhou et al. (2013, 2014a) suggested that there are also some usability aspects that used to be important with feature phones and are still important with smartphones, but in a different way. One of these aspects is their simplified design with the ease of getting help (Zhou et al., 2013). Accordingly, the complexity of menus in smartphones persists or even increases due to the smartphones' general complexity and multiple functionalities. According to Zhou et al. (2012), older adults have difficulty switching between multiple start screens, organizing applications, and closing applications during multitasking, despite the advantages of a bigger screen size.

[Insert Table 3 about here]

\subsection{Research questions}

Despite the heretofore presented advancements in the research on mobile phone UI design for older adults, to our knowledge, there has been no systematic study exploring how, and to what extent, these research findings and recommendations have been included in the available design guidelines and checklists for feature phones and smartphones. For this reason, we investigated the design guidelines and checklists for the usability dimensions of age-friendly mobile phone design and their changes over time. 
Specifically, the following research questions will be addressed in the present study:

RQ1: What are the differences between the design guidelines and checklists in terms of the number of usability dimensions and categories?

RQ2: What are the changes in the number of usability dimensions and categories in the design guidelines and checklists in terms of time (RQ2a) and the type of device (RQ2b)?

RQ3: What usability categories of mobile phone design for older adults have appeared in the published design guidelines and checklists for mobile phones?

RQ4: What are the changes in the relative importance of the usability dimensions included in the design guidelines and checklists in terms of time (RQ4a) and type of device (RQ4b)?

\section{Empirical Part}

\subsection{Procedure and method}

The data collection and analysis for this study proceeded in four stages (Figure 1). First, a set of design guidelines and checklists for older adults was identified in the literature and selected for examination. Second, to assess what aspects of usability are addressed by the design guidelines and checklists, a coding scheme was developed according to the results of the review of the usability dimensions and checklists identified in the literature and presented in Section 2. Third, the items included in the design guidelines and checklists were allocated to the usability dimensions and categories via expert coding using the coding scheme developed in the second stage. The details of the three stages of data collection, which were followed by the fourth stage of data analysis, are presented in the next subsections.

\subsection{Identification and selection of design guidelines and checklists}

We conducted a systematic search of the literature to retrieve all relevant studies that included various sets of items that serve as guidelines or heuristics for designing and/or evaluating how mobile phones and smartphones are tailored to the specific needs of older adults. The following inclusion criteria for our literature search were applied: (1) the design guideline or checklist 
focuses on older adults; (2) the design guideline or checklist deals either with mobile phones, touchscreen-based mobile phones, or smartphones; (3) the design guideline or checklist can also be in the form of a heuristic checklist or usability checklist; (4) the design guideline or checklist was developed for expert inspection; and (5) the design guideline or checklist is presented in a published article, chapter, book, or proceedings in the English language. Studies dealing with design guidelines or checklists that did not focus explicitly on older adults were excluded from the literature review.

The systematic search carried out in March 2015 included various bibliographical databases. First, we used the DiKUL search engine ${ }^{2}$, which offers a combined search for most information sources, such as databases, e-journals, e-books, collections, and catalogues. Second, we made queries using Google Scholar and other specific databases, such as ACM Digital Library, EBSCO host, JSTOR, MIS Quarterly, ProQuest Telecommunications, ProQuest Social Science Journals, Science Direct, Springer Link, Web of Science, and Wiley Online Library. The list of key terms included the following: design guideline, usability checklist, checklist, designing mobile phones for older adults/elderly/seniors, designing smartphones, heuristics, and heuristic evaluation. Third, we made an inquiry on three different mailing lists that professionally address the topic of this study: ageing@jiscmail.ac.uk, gerontoludicsociety@googlegroups.com, and sigcse-members@listserv.acm.org. All studies that met the inclusion criteria were obtained and reviewed in full by all authors of this study.

Overall, nine studies that met the criteria were identified, with five of them presenting checklists and four introducing design guidelines (see Table 4). With reference to the type of device, we followed the definitions and categorizations provided by the authors of the design guidelines and checklists. It was ascertained that four of them were based on feature phones, one on touchscreen-based phones, and four on smartphones. After completing the screening

\footnotetext{
${ }^{2}$ Available from http://dikul.uni-lj.si/.
} 
inspection, it was decided that the checklist of Van Biljon, Van Dyk, and Gelderblom (2010) should be excluded from further analysis, as Van Dyk, Gelderblom, Renaud, and van Biljon's (2013) checklist represented its extended version, whereas the heuristic checklist of Mi et al. (2014) was retained in the analysis, as visual impairments are among the most important limitations that affect the UI design for older adults (Fisk et al., 2009). Therefore, eight studies including design guidelines or checklists were considered as eligible for the empirical analysis.

Moreover, the preliminary review revealed that out of the eight eligible design guidelines and checklists, three design guidelines (i.e., Al-Razgan, Al-Khalifa, Al-Shahrani, \& AlAjmi, 2012; Massimi, Baecker, \& Wu, 2007; Pattison \& Stedmon, 2006) and one checklist (i.e., Van Dyk et al., 2013) were not empirically validated in the original papers. Conversely, the checklists of Silva, Jordan, and Holden (2014), Mi et al. (2014), and Calak (2013) ${ }^{3}$, as well as the design guidelines of Díaz-Bossini and Moreno (2014), were subject to empirical validation involving end-users and/or expert reviewers.

[Table 4 about here]

\subsection{Development of the coding scheme with usability dimensions and categories}

Since the screening inspection revealed that the range of items in the identified design guidelines and checklists varied from 10 to 54 (Table 4), a decision was taken at the second stage to analyze them with a coding scheme containing a less complex categorization of usability dimensions and categories. The usability dimensions and categories in the coding scheme were identified on the basis of the literature review of usability aspects of mobile phones and smartphones for older adults. Notably, two of the authors (AP and AR) of the present study individually reviewed the literature in Section 2 to identify the aspects of mobile phone age-friendly design that were conceptually or empirically addressed in the corresponding studies. After completing the individual reviews, the two authors matched their results. The

\footnotetext{
${ }^{3}$ More precisely, Calak (2013) was able to empirically validate only 9 of the 19 suggested heuristics.
} 
identified disagreements were discussed to reach consensus and determine what and how the usability aspects should be grouped into dimensions and categories. The described analytical procedure resulted in a coding scheme containing 38 categories nested within 7 usability dimensions (see Table 6).

\subsection{Coding of the items in the design guidelines and checklists}

The third stage was related to the coding of all items in the original design guidelines and checklists using the coding scheme developed in the second stage. This step was carried out by two of the authors (ST and AR) of this study and an independent usability expert. The three raters received the coding scheme with all the items enclosed in the eight design guidelines and checklists. ${ }^{4}$ In addition, they received a coding instruction guide explaining the coding rules and procedures. This guide provided descriptions of the categories to help them understand the meaning of each category. The three raters independently coded each item into one or more categories. If they assessed that an item did not fit in any of the offered categories, they could mark it as "Not classified." After the coding was complete, the data provided by the three raters were compiled into a single dataset. In cases where disagreement arose between the raters, the final coding was determined by the majority score given by the three raters. For instance, if two raters associated an item in the guidelines with the selected category and the third rater did not, the final score was based on the positive evaluation of the first two raters. If the majority score of the three raters for an item was "Not classified," the item was excluded from further analysis.

\section{Results}

Before addressing the research questions, we should first mention the great variation in the total number of items in the analyzed design guidelines and checklists (Table 4). In early 2006,

\footnotetext{
${ }^{4}$ In seven of the eight analyzed design guidelines and checklists, the items were clustered in two or more dimensions/categories. Before the inspection of the three expert raters, these dimensions/categories were removed from the classification form.
} 
Pattison and Stedmon's (2006) design guidelines included 10 items, and in 2007, Massimi et al.'s (2007) design guidelines included 12 items; however, this number peaked in 2013 with Van Dyk et al.'s (2013) introduction of the ESMAC checklist comprising 54 items. The trend of developing design guidelines with more items stopped in 2013, when Calak (2013) and DíazBossini and Moreno (2014) suggested a 19-item checklist. However, more numerous sets of items appeared again in 2014 with Silva et al.'s (2014) 35-item and Mi et al.'s (2014) 44-item design guidelines. Over the years, the average number of items was 26.3 ( $\mathrm{SD}=15.1$ ), whereas the average number of dimensions originally proposed by the authors of design guidelines and checklists was $4.7(\mathrm{SD}=1.3)$.

To answer RQ1, the number of categories and dimensions that the raters associated with the analyzed design guidelines and checklists was counted. As shown in Table 4, the average number of coded dimensions was $5.5(\mathrm{SD}=1.3)$, ranging from 4 in Al-Razgan et al. (2012) and Pattison and Stedmon (2006) to 7 in the design guidelines proposed by Van Dyk et al. (2013), Silva et al. (2014), and Mi et al. (2014). The average number of coded categories was 15.8 (SD =6.4), ranging from 8 in Massimi et al. (2007) and Pattison and Stedmon (2006) to 25 in Mi et al. (2014).

To address RQ2a and RQ2b, the average number of categories and dimensions was compared by year and type of device. Due to a small number of units in the analysis and the non-normal distribution of values, Spearman's rho $\left(r_{s}\right)$ was used for assessing a potential correlation between the year and the number of categories/dimensions (Hollander, Wolfe, \& Chicken, 2013). As shown in Table 5, the results revealed that both the average number of categories $\left(r_{s}=0.710\right)$ and dimensions $\left(r_{s}=0.543\right)$ were positively associated with time, indicating that the design guidelines had become more complex in terms of the average numbers of included usability categories and dimensions, simultaneously with the increased functional 
complexity of mobile phones..$^{5}$ The design guidelines and checklists for feature phones in comparison with those for touchscreen-based phones and smartphones had, on average, a considerably smaller number of categories $(D=-3.9)$, while the difference with reference to the average number of dimensions $(D=-0.3)$ was less pronounced (Table 5). ${ }^{6}$

[Table 5 about here]

RQ3 was investigated by counting how many categories were addressed in the eight design guidelines and checklists. The number of guidelines and checklists including the inspected categories is reported in column "N" of Table 6. The results show that out of 38 categories, 9 were included in more than half of the design guidelines and checklists: high contrast, button type, button size, button responsiveness, button positioning, font size, ease of navigation, device size, and device shape. Moreover, 11 categories were included in exactly half of the design guidelines and checklists: colors, touchscreen content layout, button shape, labeled buttons, number of buttons, simple menu, consistent menu, device material, battery charging, volume settings, and terminology. The other 18 categories were addressed by 3 or fewer design guidelines and checklists. In particular, it is surprising that display size, button feedback, and error messages were included in only three design guidelines and checklists, while font type, slower dimming, ease of text entry, function labels, and minimized nesting of menus were mentioned only in two or fewer of them.

[Table 6 about here]

\footnotetext{
${ }^{5}$ Since we used a systematic procedure to identify all suitable design guidelines and checklists published in the literature (Section 3.2), we assumed that the eight analyzed units represent the population of all available units that met the selection criteria. Thus, in the analyses, we did not run statistical significance tests.

${ }^{6}$ Due to the suggestion of Henze, Rukzio, and Boll (2011) that touchscreen-based smartphones represent the dominant format of smartphones today, as well the smallest number of units, the categories of touchscreen-based phones and smartphones were combined into one category in the analysis.
} 
To answer RQ4a, the values of Spearman's rho were calculated for the correlation between the year when the design guideline or checklist was published and the relative importance of each usability dimension, calculated as the percentage of categories within each usability dimension included in the design guidelines and checklists. ${ }^{7}$ As Table 7 shows, the strongest association was observed between the year of publication and the dimension of Touchscreen $\left(r_{s}=0.823\right)$, indicating that the usability categories associated with touchscreens have become relevant only very recently. Furthermore, a strong association was revealed between the dimensions of Text $\left(r_{s}=0.676\right)$ and Content $\left(r_{s}=0.552\right)$, with positive values of Spearman's rho indicating that the relative importance of both dimensions increased over the years. Again, a positive, albeit moderate, correlation was also found between the dimensions of Screen $\left(r_{s}=0.373\right)$ and Menu $\left(r_{s}=0.381\right)$, while the relative importance of Exterior did not change much over time $\left(r_{s}=0.037\right)$. The only negative correlation was observed for the dimension of the Keypad $\left(r_{s}=-0.158\right)$, suggesting that the proportion of items associated with the various aspects of keypads slightly diminished across the years.

[Table 7 about here]

The last research question (RQ4b) was proposed to look at how the type of device addressed by a selected design guideline or checklist was associated with the usability dimensions of mobile phones for older adults. The analysis of differences in the average percentages of categories included in the usability dimensions between feature phones and touchscreen-based phones and smartphones showed that the largest differences were observed for the dimensions of Screen $(D=-33.3$ percentage points), Exterior $(D=-35.6$ percentage points), followed by the dimension of Text $(D=-17.8$ percentage points) and Touchscreen $(D$

\footnotetext{
${ }^{7}$ The decision to analyze the percentage of categories addressed within each dimension stemmed from the fact that the dimensions did not have an equal number of categories (Table 6). For example, the dimension of Keypad included eight categories, while that of Text included only three categories.
} 
$=-16.0$ percentage points), with negative differences, indicating that on average, the proportion of categories associated with these dimensions was larger in the design guidelines and checklists for touchscreen-based phones and smartphones (Table 7). Conversely, the categories for the dimension of Menu seemed to be, on average, more frequently included in the design guidelines and checklists for feature phones $(D=17.3$ percentage points), while no substantial differences were ascertained in terms of the dimensions of Keypad ( $D=5.8$ percentage points) and Content $(D=-5.3$ percentage points). Overall, the results also indicated that the largest proportion of categories was included for the dimension of Keypad (54.7\%), followed by Exterior (50.0\%) and Menu (42.5\%). Other dimensions included approximately one third of the potential categories: Screen (37.5\%), Text (33.3\%), Touchscreen (30.0\%), and Content $(30.0 \%)$

\section{Discussion and Conclusions}

\subsection{Research findings}

This study provided an overview of the existing research on the usability of mobile phone interfaces for older adults, with the aim of identifying what dimensions of usability were included in the studied design guidelines and checklists, how their presence has changed over time, and whether the dimensions and categories related differently to feature phones and smartphones. The empirical analysis was based upon eight design guidelines and checklists published between 2006 and 2014. Three of them dealt with feature phones and five with touchscreen-based phones or smartphones.

In response to RQ1, we found that on average the analyzed design guidelines and checklists included between 5 and 6 coded dimensions $(M=5.5)$ with small variation between the guidelines. Interestingly, the average number of coded dimensions did not differ much from the average number of dimensions that were originally defined in the analyzed design guidelines and checklists $(\mathrm{M}=4.7)$. Conversely, a larger variability was found between 
guidelines in terms of the number of included categories. This was somehow expected due to a higher average number of categories $(M=15.8)$. Further, when addressing RQ2, in terms of time (RQ2a) and the type of device (RQ2b), we observed that the analyzed design guidelines and checklists had become more complex regarding the average number of included usability categories and dimensions. Notably, on average, the number of included dimensions and categories in design guidelines and checklists increased from 2006 to 2014. Likewise, smartphone-related design guidelines and checklists also had on average a higher number dimensions and categories than the ones dedicated to feature phones. This main finding might stem from at least two factors. The first factor is that the number of studies on mobile phone design for the general population as well as for older adults had increased, providing scholars with more elaborate and comprehensive knowledge for the development of new, or the refinement of existing, design guidelines or checklists (Wangenheim et al., 2016). A good illustration of this development is the ESMAC checklist (van Dyk et al., 2013), which is an extension of the SMAC checklist (Van Biljon et al., 2010), including a larger number of both items and dimensions. The second factor is that usability research has been following the mobile phone industry, which has developed service and interface innovations at an increasing pace (Cecere et al., 2015).

Regarding RQ3, asking what categories were included in the studied design guidelines and checklists, we found that the most frequently mentioned categories were related to selected visual and haptic issues (e.g., high contrast, font size, button type, button size, button positioning). By contrast, the least frequently occurring categories were related to the elements of textual interface (e.g., ease of text entry, button's feedback, font type, error messages, and function labels) and to screen and menu aspects, such as high screen resolution, slower screen dimming and minimized nesting of menus. In addition, it was observed that only the keypad and exterior dimensions were represented in the guidelines with half or more of the respective 
categories in the coding scheme. This result suggest that despite the increased complexity in terms of dimensions and categories, there have been many usability dimensions of age-friendly mobile phone UI design which could be better covered by the authors of the guidelines and, thus, warrant further development in the future.

RQ4 tackles the changes in the importance of various dimensions both over time (RQ4a) and in terms of the type of device (RQ4b). Our analysis of the correlations between time and the proportion of categories included in each revealed that the largest positive increase was associated with the dimension of Touchscreen (i.e., which was only a part of the design guidelines published in 2012 or later). A strong positive correlation over time was also observed for the dimensions of Text and Content, while for Screen and Menu, the correlation was somewhat lower, and for the dimension of Exterior, the positive change was minimal. Conversely, the importance of Keypad decreased during the same period. The decreased role of device-based controllers, such as keypad position, button shape, and/or button size, seems to be directly related to the introduction of touchscreen-based controllers, which have become increasingly standardized (e.g., smartphones have generally only a couple of buttons) and which, if needed, can be customized to the needs of older adults - as in the case of virtual buttons on smartphone launchers for older adults (Balata, Mikovec, \& Slavicek, 2015).

Concerning RQ4b, the number of usability dimensions of the design guidelines and checklists for feature phones and smartphones accentuate dimensions differently. First, the guidelines and checklists included a higher proportion of categories in the dimensions of Screen, Touchscreen, Text, and Content for touchscreen-based phones or smartphones, whereas Keypad and Menus were more important dimensions for feature phones than for smartphones. These findings seem to correspond with the literature, which suggests that although smartphones are provided with larger and more high-definition displays, the properties of touchscreens and text become even more important because they provide information and 
control on one screen (Hwangbo et al., 2013). Consequently, without screen-based controllers, the interaction with a smartphone UI would be limited or almost impossible. We also ascertained that only two out of five design guidelines and checklists for smartphones dealt with gestures and targets, whereas feedback was addressed by three out of five.

Second, we found that the importance of the Exterior dimension was higher in the case of smartphones than features phones. Design guidelines and checklists for touchscreen-based phones and smartphones put even more importance on characteristics such as device size, shape, and material, as well as mode of battery charging, availability of external volume buttons, and hearing aid compatibility. With reference to the size, shape, and weight of smartphones, our findings are in line with a recent study by Cecere et al. (2015), demonstrating that all three characteristics of smartphones are still important in terms of product differentiation; moreover, there seems to be a recent increase in the degree of product differentiation related to screen size and width.

Third, we noticed that the importance of the Menu and Keypad dimensions decreased when moving from feature phones to smartphones. Our results indicate that it is somehow assumed in the design guidelines and checklists for smartphones, which may not comply with user experience, that touchscreens, due to their size and other UI characteristics (e.g., highresolution icons), can offer much better menu transparency, which allows older adults to see a larger part of the menu at one time. This would provide users with a better spatial orientation in menus and easier navigation. In fact, the complexity of menus in smartphones resumes or even increases due to the smartphones' general complexity and multiple functionalities. The less central role of the keypad is not surprising if we bear in mind Henze et al.'s (2011) observation that a touchscreen with a few physical buttons has been the dominant design of smartphone devices since Apple entered the market with the first iPhone model in 2007. 
Lastly, it is also worth noting that the average proportion of categories for the dimension of Content was higher for smartphones. It might be that terminology, labeling issues, help functions, and the clarity of error messages became even more important as elements of mobile phone usability for older adults, with the increased complexity of smartphone user interfaces.

\subsection{Limitations}

Even though this study presents original insights into the content and relevance of usability dimensions for age-friendly mobile phone design by investigating design guidelines and checklists, its findings are subject to some limitations. First, as the focus was only on design guidelines and checklists for older adults, we were unable to determine the extent to which the findings were influenced by more general trends and changes in mobile phone interaction design. Although this might be a relevant question, it was beyond the scope of the present study. Second, one of the aims of this study was to compare the importance of dimensions and categories of usability. This obviously implies a reduction of complexity at the empirical level of analysis, leading to an information loss problem in the data collection. Further studies could deepen our understanding of the topic by providing a more fine-grained classification, which could also be based on more evaluators. Third, the overviews of dimensions and categories in the coding scheme and the coding of the design guidelines and checklists were carried out by a limited number of raters. Although the raters were experts in the field of mobile phone interaction design, involving more raters would probably increase the validity of the analytical procedures and related findings. Fourth, in the review of design guidelines and checklists it was not possible to determine how the notion of "older adult" was defined in different studies. It may be that the authors used different definitions of this population, which may have implications for the confidence gained in this study. Fifth, this study did not assess the empirical validity and applicability of the design guidelines. In fact, it only ascertained that half of the analyzed papers actually provided some evidence for the validation of the heuristics included 
in the design guidelines. This also points us to the issue of the usability of the guidelines themselves and to the question about how useful they are to designers. Although these questions are outside the scope of this study, it is evident that they are worthy of further investigation.

\subsection{Concluding remarks and implications}

Since older adults represent a growing population in the mobile phone market (Berenguer et al., 2017) and the development cycle for mobile phones and applications is fairly short (Wangenheim et al., 2016), adopting lightweight evaluation techniques can be beneficial for understanding how older adults' needs and requirements are addressed by the developers in an iterative design and engineering process. One of the main reasons why older adults experience problems with mobile phone use is that there is a discrepancy between the design of devices and users' needs (e.g., Dolničar, Šetinc, \& Petrovčič, 2016; Hwangbo et al., 2013; Kurniawan, 2008; Renaud \& van Biljon, 2010; Zhou, Rau, \& Salvendy, 2014b). Indeed, older adults frequently experience issues while using mobile phones that reduce their ease-of-use as one of the main predictors of mobile phone usage (Motti et al., 2013). However, in order to be a useful tool for researchers and developers to inspect mobile phone UIs, design guidelines and checklists should embrace and address usability dimensions and categories, which were identified in prior literature as relevant for age-friendly mobile phone design.

Overall, the results of the present study show that over time, the analyzed design guidelines and checklists have become more complex and inclusive in terms of the number of included usability categories and dimensions. They cover more dimensions of usability and seem to be more comprehensive because the dimensions are addressed with more usability categories. Such a conclusion can also be reached for the comparison between guidelines for feature phones and smartphones. Hence, it seems that designers and scholars have quite successfully re-evaluated in the guidelines how cognitive, perceptual, and physical limitations of older adults should be addressed in the design of UI for smartphones. In this sense, we can 
suggest to practitioners who want to perform heuristic evaluations that recent guidelines for smartphones, such as Díaz-Bossini and Moreno (2014), Silva et al. (2014), and Mi et al. (2014), are valuable resources for expert reviews.

Nevertheless, it should be noted that we also identified aspects of usability that need to be expanded in the guidelines. Only the keypad and exterior dimensions were addressed with half or more of the respective categories in the coding scheme. In addition, even though topics such as display size, ease of text entry, font type, target/icon properties, clarity of error messages, minimized menu nesting, and function labels have been subjects of importance in many scholarly investigations, they are not extensively covered in the analyzed design guidelines and checklists. Our findings can be used as input for further research on, and development of, (existing) guidelines along these topics.

Yet these advances should not only be technology-driven and focused on product innovations introduced by the mobile phone industry, such as by leading mobile operating system (OS) developers promoting OS-specific UI design principles and styles. Rather, the advancements should also be human-centric, taking into account the needs and resources of older adults, ascertained in scholarly research. While some of the limitations of older adults will not change much over time, such as memory loss, failing eyesight, or hand trembling, their technological skills are expected to improve generation by generation, compelling researchers and designers to consider what will be the appropriate design of mobile phone UIs in the future. This could be done by studying both changes in the characteristics of users over time and findings from the usability studies with older adults alongside the technological development of smartphones.

In this manner, future guidelines and checklists should be constantly scrutinized and validated to reflect the above-mentioned changes. In fact, validation in the sense of repeatability and reproducibility seems to be one of the weakest aspects of the analyzed design guidelines 
and checklists. Notably, only half of them were validated in the original papers and even fewer used different empirical methods as a basis for establishing evidence that the guidelines had fulfilled their intended requirements. Thus, more attempts should be made to verify the usefulness of the existing design guidelines and checklists. As in the study of Silva, Holden, and Jordan (2015), validation could include a heuristic evaluation of a wide array of mobile phone devices and services for older adults as well as expert evaluations to provide feedback to the researchers on the usefulness, strengths, and gaps of the heuristics list. Given that some of the analyzed design guidelines already contain more than 30 heuristics, we suggest that in future revisions of guidelines, more effort should be put into assuring a higher degree of repeatability and reproducibility of existing guidelines, rather than developing (even) more numerous sets of items. Last but not least, we should not forget that inspection methods, and in particular heuristic evaluation, have become popular due to their so-called "discount" characteristics (Dumas \& Salzman, 2006). If they become too complex and difficult to apply, they will very likely lose their most favorable utility among design practitioners dealing with older adults.

\section{Acknowledgements}

The authors would like to thank Matjaž Debevc, Ph.D., for offering his assistance in the data collection process, and the reviewers of this paper for their helpful comments and suggestions to improve this paper. This study received public financial support from research grants (number L5-6818 and L5-7626) administered through the Slovenian Research Agency (ARRS).

\section{References}

Abdul Razak, F. H., Razak, N. A., Wan Adnan, W. A., \& Ahmad, N. A. (2013). How Simple is Simple: Our Experience with Older Adult Users. In Proceedings of the 11th Asia Pacific Conference on Computer Human Interaction (pp. 379-387). New York, NY, USA: ACM. https://doi.org/10.1145/2525194.2525307 
Al-Razgan, M. S., Al-Khalifa, H. S., Al-Shahrani, M. D., \& AlAjmi, H. H. (2012). TouchBased Mobile Phone Interface Guidelines and Design Recommendations for Elderly People: A Survey of the Literature. In T. Huang, Z. Zeng, C. Li, \& C. S. Leung (Eds.), Neural Information Processing (pp. 568-574). Berlin: Springer.

Armstrong, N., Nugent, C., Moore, G., \& Finlay, D. (2010). Using smartphones to address the needs of persons with Alzheimer's disease. Annals of Telecommunications, 65(9-10), 485-495. https://doi.org/10.1007/s12243-010-0165-3

Arning, K., \& Ziefle, M. (2007). Barriers of Information Access in Small Screen Device Applications: The Relevance of User Characteristics for a Transgenerational Design. In C. Stephanidis \& M. Pieper (Eds.), Universal Access in Ambient Intelligence Environments (pp. 117-136). Berlin: Springer. Retrieved from http://link.springer.com/chapter/10.1007/978-3-540-71025-7_9

Balata, J., Mikovec, Z., \& Slavicek, T. (2015). KoalaPhone: touchscreen mobile phone UI for active seniors. Journal on Multimodal User Interfaces, 1-11. https://doi.org/10.1007/s12193-015-0188-1

Bay, S., \& Ziefle, M. (2004). Effects of Menu Foresight on Information Access in Small Screen Devices. Proceedings of the Human Factors and Ergonomics Society Annual Meeting, 48(16), 1841-1845. https://doi.org/10.1177/154193120404801611

Berenguer, A., Goncalves, J., Hosio, S., Ferreira, D., Anagnostopoulos, T., \& Kostakos, V. (2017). Are Smartphones Ubiquitous?: An in-depth survey of smartphone adoption by seniors. IEEE Consumer Electronics Magazine, 6(1), 104-110. https://doi.org/10.1109/MCE.2016.2614524

Boulos, M. N. K., Wheeler, S., Tavares, C., \& Jones, R. (2011). How smartphones are changing the face of mobile and participatory healthcare: an overview, with example 
from eCAALYX. Biomedical Engineering Online, 10, 24.

https://doi.org/10.1186/1475-925X-10-24

Boustani, S. (2010). Designing touch-based interfaces for the elderly (Bachelor's thesis). University of Sydney.

Bruder, C., Blessing, L., \& Wandke, H. (2007). Training the Elderly in the Use of Electronic Devices. In Proceedings of the 4th International Conference on Universal Access in Human Computer Interaction: Coping with Diversity (pp. 637-646). Berlin: Springer. Retrieved from http://dl.acm.org/citation.cfm?id=1766311.1766385

Butlewski, M., Tytyk, E., Wróbel, K., \& Miedziarek, S. (2014). Heuristics in Ergonomic Design of Portable Control Devices for the Elderly. In Universal Access in HumanComputer Interaction. Aging and Assistive Environments (pp. 24-33). Berlin: Springer. https://doi.org/10.1007/978-3-319-07446-7_3

Calak, P. (2013). Smartphone Evaluation Heuristics for Older Adults. The University of Guelph, Guelph, Ontario, Canada. Retrieved from https://atrium.lib.uoguelph.ca/xmlui/handle/10214/5610

Callegaro, M., Lozar Manfreda, K., \& Vehovar, V. (2015). Web survey methodology. London: Sage.

Caprani, N., O’Connor, N. E., \& Gurrin, C. (2012). Touch Screens for the Older User. In F. Auat Cheein (Ed.), Assistive Technologies (pp. 104-128). InTech.

Cecere, G., Corrocher, N., \& Battaglia, R. D. (2015). Innovation and competition in the smartphone industry: Is there a dominant design? Telecommunications Policy, 39(34), 162-175. https://doi.org/10.1016/j.telpol.2014.07.002

Chen, K., Chan, A. H. S., \& Tsang, S. N. H. (2013). Usage of mobile phones amongst elderly people in Hong Kong. Proceedings of the International MultiConference of Engineers and Computer Scientists 2013, (Vol II), 1016-1019. 
Díaz-Bossini, J.-M., \& Moreno, L. (2014). Accessibility to Mobile Interfaces for Older People. Procedia Computer Science, 27, 57-66. https://doi.org/10.1016/j.procs.2014.02.008

Dickinson, A., Arnott, J., \& Prior, S. (2007). Methods for human - computer interaction research with older people. Behaviour \& Information Technology, 26(4), 343-352. https://doi.org/10.1080/01449290601176948

Dolničar, V., Šetinc, M., \& Petrovčič, A. (2016). Toward an age-friendly design of smartphone interfaces: the usability test of a launcher for older adults. Uporabna Informatika, XXIV(24), 4-15.

Dumas, J. S., \& Salzman, M. C. (2006). Usability Assessment Methods. Reviews of Human Factors and Ergonomics, 2(1), 109-140. https://doi.org/10.1177/1557234X0600200105

Fisk, A. D., Rogers, W. A., Charness, N., Czaja, S. J., \& Sharit, J. (2009). Designing for Older Adults: Principles and Creative Human Factors Approaches (2nd ed.). Boca Raton: CRC Press.

Furuki, K., \& Kikuchi, Y. (2013). Approach to Commercialization of Raku-Raku Smartphone. FUJITSU Scientific \& Technical Journal, 49(2), 196-201.

Gao, J., \& Koronios, A. (2010). Mobile Application Development for Senior Citizens. In PACIS 2010 Proceedings (pp. 214-223). Taipei, Taiwan.

Gao, Q., Ebert, D., Chen, X., \& Ding, Y. (2015). Design of a Mobile Social Community Platform for Older Chinese People in Urban Areas. Human Factors and Ergonomics in Manufacturing \& Service Industries, 25(1), 66-89. https://doi.org/10.1002/hfm.20523

Haigh, R. (1993). The ageing process: a challenge for design. Applied Ergonomics, 24(1), 914. https://doi.org/10.1016/0003-6870(93)90153-Z 
Harada, S., Sato, D., Takagi, H., \& Asakawa, C. (2013). Characteristics of Elderly User Behavior on Mobile Multi-touch Devices. In P. Kotzé, G. Marsden, G. Lindgaard, J. Wesson, \& M. Winckler (Eds.), Human-Computer Interaction - INTERACT 2013 (pp. 323-341). Berlin: Springer.

Hasegawa, S., Omori, M., Matsunuma, S., \& Miyao, M. (2006). Aging effects on the visibility of graphic text on mobile phones. Gerontechnology, 4(4), 200-208. https://doi.org/10.4017/gt.2006.04.04.004.00

Hassan, H., \& Nasir, M. H. N. (2008). The Use of Mobile Phones by Older Adults: A Malaysian Study. SIGACCESS Access. Comput., (92), 11-16. https://doi.org/10.1145/1452562.1452564

Henze, N., Rukzio, E., \& Boll, S. (2011). 100,000,000 Taps: Analysis and Improvement of Touch Performance in the Large. In Proceedings of the 13th International Conference on Human Computer Interaction with Mobile Devices and Services (pp. 133-142). New York, NY, USA: ACM. https://doi.org/10.1145/2037373.2037395

Hollander, M., Wolfe, D. A., \& Chicken, E. (2013). Nonparametric Statistical Methods (3rd ed.). New York: Wiley.

Holzinger, A., Searle, G., Kleinberger, T., Seffah, A., \& Javahery, H. (2008). Investigating Usability Metrics for the Design and Development of Applications for the Elderly. In K. Miesenberger, J. Klaus, W. Zagler, \& A. Karshmer (Eds.), Computers Helping People with Special Needs (pp. 98-105). Springer Berlin Heidelberg. Retrieved from http://link.springer.com/chapter/10.1007/978-3-540-70540-6_13

Holzinger, A., Searle, G., \& Nischelwitzer, A. (2007). On Some Aspects of Improving Mobile Applications for the Elderly. In Proceedings of the 4th International Conference on Universal Access in Human Computer Interaction: Coping with Diversity (pp. 923- 
932). Berlin, Heidelberg: Springer-Verlag. Retrieved from

http://dl.acm.org/citation.cfm?id=1766311.1766418

Hwangbo, H., Yoon, S. H., Jin, B. S., Han, Y. S., \& Ji, Y. G. (2013). A Study of Pointing Performance of Elderly Users on Smartphones. International Journal of HumanComputer Interaction, 29(9), 604-618. https://doi.org/10.1080/10447318.2012.729996

Irie, T., Matsunaga, K., \& Nagano, Y. (2005). Universal Design Activities for Mobile Phone: Raku Raku Phone. FUJITSU Scientific \& Technical Journal, 41(1), 78-85.

Ji, Y. G., Park, J. H., Lee, C., \& Yun, M. H. (2006). A Usability Checklist for the Usability Evaluation of Mobile Phone User Interface. International Journal of HumanComputer Interaction, 20(3), 207-231. https://doi.org/10.1207/s15327590ijhc2003_3

Joe, J., \& Demiris, G. (2013). Older Adults and Mobile Phones for Health: A Review. Journal of Biomedical Informatics, 46(5), 947-954. https://doi.org/10.1016/j.jbi.2013.06.008

Jones, M., \& Marsden, G. (2006). Mobile interaction design (Vol. 10). Chichester: John Wiley \& Sons.

Kause, M. (2013). “I just wanted a beautiful phone” Checklist-based evaluation of smartphones usability for the elderly users. University of Tamper. Retrieved from http://tampub.uta.fi/handle/10024/94964

Kim, H., Heo, J., Shim, J., Kim, M., Park, S., \& Park, S. (2007). Contextual Research on Elderly Users' Needs for Developing Universal Design Mobile Phone. In Proceedings of the 4th International Conference on Universal Access in Human Computer Interaction: Coping with Diversity (pp. 950-959). Berlin: Springer. Retrieved from http://dl.acm.org/citation.cfm?id=1766311.1766421

Kobayashi, M., Hiyama, A., Miura, T., Asakawa, C., Hirose, M., \& Ifukube, T. (2011). Elderly User Evaluation of Mobile Touchscreen Interactions. In Proceedings of the 
13th IFIP TC 13 International Conference on Human-computer Interaction - Volume Part I (pp. 83-99). Berlin: Springer. Retrieved from http://dl.acm.org/citation.cfm?id=2042053.2042065

Koutsourelakis, C., \& Chorianopoulos, K. (2010). Icons in mobile phones: Comprehensibility differences between older and younger users. Information Design Journal (IDJ), 18(1), 22-35. https://doi.org/10.1075/idj.18.1.03cho

Kurniawan, S. (2006). An Exploratory Study of How Older Women Use Mobile Phones. In Proceedings of the 8th International Conference on Ubiquitous Computing (pp. 105122). Berlin: Springer. https://doi.org/10.1007/11853565_7

Kurniawan, S. (2008). Older People and Mobile Phones: A Multi-method Investigation. International Journal of Human Computer Studies, 66(12), 889-901. https://doi.org/10.1016/j.ijhcs.2008.03.002

Lee, J.-H., Poliakoff, E., \& Spence, C. (2009). The Effect of Multimodal Feedback Presented via a Touch Screen on the Performance of Older Adults. In Proceedings of the 4th International Conference on Haptic and Audio Interaction Design (pp. 128-135). Berlin: Springer. https://doi.org/10.1007/978-3-642-04076-4_14

Lee, Y. S. (2007). A Survey of Mobile Phone Use in Older Adults. Proceedings of the Human Factors and Ergonomics Society Annual Meeting, 51(1), 1-5. https://doi.org/10.1177/154193120705100101

Leitao, R., \& Silva, P. A. (2012). Target and spacing sizes for smartphone user interfaces for older adults : design patterns based on an evaluation with users. Presented at the Conference on Pattern Languages of Programs, Tucson, Arizona. Retrieved from http://www.hillside.net/plop/2012/papers/Group\%201\%20$\% 20$ Elk/Target $\% 20$ and $\% 20$ Spacing\%20Sizes\%20for\%20Smartphone $\% 20$ User\%20int erfaces\%20for\%20Older\%20Adults\%20- 
$\% 20$ Design $\% 20$ patterns $\% 20$ Based $\% 20$ on\%20an\%20Evaluation\%20with\%20Users.pd f\#!

Leung, R., Findlater, L., McGrenere, J., Graf, P., \& Yang, J. (2010). Multi-Layered Interfaces to Improve Older Adults' Initial Learnability of Mobile Applications. ACM Transactions on Accessible Computing, 3(1), 1-30. https://doi.org/10.1145/1838562.1838563

Lorenz, A., \& Oppermann, R. (2009). Mobile health monitoring for the elderly: Designing for diversity. Pervasive and Mobile Computing, 5(5), 478-495. https://doi.org/10.1016/j.pmcj.2008.09.010

Maguire, M., \& Osman, Z. (2003). Designing for older and inexperienced mobile phone users. In Proceedings of HCI International (pp. 22-27).

Mann, W. C., Helal, S., Davenport, R. D., Justiss, M. D., Tomita, M. R., \& Kemp, B. J. (2004). Use of cell phones by elders with impairments: Overall appraisal, satisfaction, and suggestions. Technology and Disability, 16(1), 49-57.

Massimi, M. (2007). Participatory design of mobile phone software for seniors. University of Toronto, Toronto, Ontario, Canada. Retrieved from http://www.dgp.toronto.edu/ mikem/pubs/Massimi-MScThesis.pdf

Massimi, M., Baecker, R. M., \& Wu, M. (2007). Using Participatory Activities with Seniors to Critique, Build, and Evaluate Mobile Phones. In Proceedings of the 9th International ACM SIGACCESS Conference on Computers and Accessibility (pp. 155-162). New York, NY, USA: ACM. https://doi.org/10.1145/1296843.1296871

Mi, N., Cavuoto, L. A., Benson, K., Smith-Jackson, T., \& Nussbaum, M. A. (2014). A Heuristic Checklist for an Accessible Smartphone Interface Design. Universal Access in the Information Society, 13(4), 351-365. https://doi.org/10.1007/s10209-013-03214 
Motti, L. G., Vigouroux, N., \& Gorce, P. (2013). Interaction Techniques for Older Adults Using Touchscreen Devices: A Literature Review. In Proceedings of the 25th IEME Conference Francophone on L'Interaction Homme-Machine (pp. 125-134). New York, NY, USA: ACM. https://doi.org/10.1145/2534903.2534920

Ofcom. (2015). Adults' Media Use and Attitudes Report. London: Ofcom. Retrieved from http://stakeholders.ofcom.org.uk/binaries/research/media-literacy/media-lit10years/2015_Adults_media_use_and_attitudes_report.pdf

Olwal, A., Lachanas, D., \& Zacharouli, E. (2011). OldGen: Mobile Phone Personalization for Older Adults. In Proceedings of the SIGCHI Conference on Human Factors in Computing Systems (pp. 3393-3396). New York, NY, USA: ACM. https://doi.org/10.1145/1978942.1979447

Parush, A., \& Yuviler-Gavish, N. (2004). Web navigation structures in cellular phones: the depth/breadth trade-off issue. International Journal of Human-Computer Studies, 60(5-6), 753-770. https://doi.org/10.1016/j.ijhcs.2003.10.010

Pattison, M., \& Stedmon, A. W. (2006). Inclusive Design and Human Factors: Designing Mobile Phones for Older Users. PsychNology Journal, 4(3), 267-284.

Pijukkana, K., \& Sahachaisaeree, N. (2010). Factor determining functional perception on technology-driven product design: a case study on mobile phone for the elderly. Procedia - Social and Behavioral Sciences, 5, 1288-1293. https://doi.org/10.1016/j.sbspro.2010.07.277

Plaza, I., Martín, L., Martin, S., \& Medrano, C. (2011). Mobile Applications in an Aging Society: Status and Trends. Journal of Systems and Software, 84(11), 1977-1988. https://doi.org/10.1016/j.jss.2011.05.035 
Renaud, K., \& van Biljon, J. (2010). Worth-centred Mobile Phone Design for Older Users. Universal Access in the Information Society, 9(4), 387-403. https://doi.org/10.1007/s10209-009-0177-9

Silva, P. A., Holden, K., \& Jordan, P. (2015). Towards a List of Heuristics to Evaluate Smartphone Apps Targeted at Older Adults: A Study with Apps that Aim at Promoting Health and Well-Being. In T. X. Bui \& R. H. S. Jr (Eds.), 48th Hawaii International Conference on System Sciences, HICSS 2015, Kauai, Hawaii, USA, January 5-8, 2015 (pp. 3237-3246). IEEE. https://doi.org/10.1109/HICSS.2015.390

Silva, P. A., Holden, K., \& Nii, A. (2014). Smartphones, Smart Seniors, But Not-So-Smart Apps: A Heuristic Evaluation of Fitness Apps. In D. D. Schmorrow \& C. M. Fidopiastis (Eds.), Foundations of Augmented Cognition. Advancing Human Performance and Decision-Making through Adaptive Systems (pp. 347-358). Berlin: Springer.

Silva, P. A., Jordan, P., \& Holden, K. (2014). Something Old, Something New, Something Borrowed: Gathering Experts' Feedback While Performing Heuristic Evaluation with a List of Heuristics Targeted at Older Adults. In Proceedings of the 2014 Workshops on Advances in Computer Entertainment Conference (p. 19:1-19:8). New York, NY, USA: ACM. https://doi.org/10.1145/2693787.2693804

Smith, A. (2013). Older Adults and Technology Use. Washington, DC: Pew Research Center. Retrieved from http://www.pewinternet.org/2014/04/03/older-adults-and-technologyuse/

Smith, A. (2015). U.S. Smartphone Use in 2015. Washington, DC: Pew Research Center. Retrieved from http://www.pewinternet.org/2015/04/01/us-smartphone-use-in-2015/ 
Stössel, C., Wandke, H., \& Blessing, L. (2010). Gestural interfaces for elderly users: help or hindrance? In Gesture in embodied communication and human-computer interaction (pp. 269-280). Berlin: Springer.

Sulaiman, S., \& Sohaimi, I. S. (2010). An investigation to obtain a simple mobile phone interface for older adults. In 2010 International Conference on Intelligent and Advanced Systems (ICIAS) (pp. 1-4). Kuala Lumpur, Malaysia: IEEE. https://doi.org/10.1109/ICIAS.2010.5716254

Van Biljon, J., Van Dyk, T., \& Gelderblom, H. (2010). Mobile phone adoption : optimising value for older adults in a developing country. In J. Steyn (Ed.), 4th International IDIA Development Informatics Conference. Cape Town, South Africa: IDIA, Monash University. Retrieved from http://uir.unisa.ac.za/handle/10500/5396

van Dyk, T., Gelderblom, H., Renaud, K., \& van Biljon, J. (2013). Mobile Phones for the Elderly: a design framework. In J. Steyn \& A. G. Van der Vyver (Eds.), Public and private access to ICTs in developing regions. Proceedings of the 7th International Development Informatics Association Conference (pp. 85-102). Bangkok, Thailand.

Waloszek, G. (2010). Interaction design guide for touchscreen applications (experimental). SAP Design Guild, Version 0.5. Retrieved from http://www.sapdesignguild.org/goodies/TSDesignGL/TSDesignGL.pdf

Wang, Q. (2008). The effects of interface design about mobile phones on older adults' usage. In 2008 International Conference on Wireless Communications, Networking and Mobile Computing, WiCOM 2008. https://doi.org/10.1109/WiCom.2008.2945

Wangenheim, C. G. von, Witt, T. A., Borgatto, A. F., Nunes, J. V., Lacerda, T. C., Krone, C., \& Souza, L. de O. (2016). A Usability Score for Mobile Phone Applications Based on Heuristics. International Journal of Mobile Human Computer Interaction (IJMHCI), 8(1), 23-58. https://doi.org/10.4018/IJMHCI.2016010102 
Zhou, J., Rau, P. L. P., \& Salvendy, G. (2013). A Qualitative Study of Older Adults' Acceptance of New Functions on Smart Phones and Tablets. In P. L. P. Rau (Ed.), Cross-Cultural Design. Methods, Practice, and Case Studies (pp. 525-534). Berlin: Springer. Retrieved from http://link.springer.com/chapter/10.1007/978-3-642-391439_59

Zhou, J., Rau, P. L. P., \& Salvendy, G. (2014a). Age-related Difference in the Use of Mobile Phones. Univers. Access Inf. Soc., 13(4), 401-413. https://doi.org/10.1007/s10209013-0324-1

Zhou, J., Rau, P. L. P., \& Salvendy, G. (2014b). Older Adults’ Text Entry on Smartphones and Tablets: Investigating Effects of Display Size and Input Method on Acceptance and Performance. International Journal of Human-Computer Interaction, 30(9), 727739. https://doi.org/10.1080/10447318.2014.924348

Zhou, J., Rau, P.-L. P., \& Salvendy, G. (2012). Use and Design of Handheld Computers for Older Adults: A Review and Appraisal. International Journal of Human-Computer Interaction, 28(12), 799-826. https://doi.org/10.1080/10447318.2012.668129

Ziefle, M. (2010). Information presentation in small screen devices: the trade-off between visual density and menu foresight. Applied Ergonomics, 41(6), 719-730. https://doi.org/10.1016/j.apergo.2010.03.001

Ziefle, M., \& Bay, S. (2005). How older adults meet complexity: Aging effects on the usability of different mobile phones. Behaviour \& Information Technology, 24(5), 375-389. https://doi.org/10.1080/0144929042000320009

Ziefle, M., \& Bay, S. (2006). How to Overcome Disorientation in Mobile Phone Menus: A Comparison of Two Different Types of Navigation Aids. Human-Computer Interaction, 21(4), 393-433. https://doi.org/10.1207/s15327051hci2104_2 
Ziefle, M., Künzer, A., \& Bodendieck, A. (2004). The impact of user characteristics on the utility of adaptive help systems. In Proceedings of the 6th International Conference on Work With Computing Systems (pp. 71-76). Kuala Lumpur: Damai Sciences. 


\section{Tables}

Table 1. Key findings of studies with older adults related to device-based and screen-based interaction elements of feature phones

\begin{tabular}{|c|c|c|}
\hline Interaction elements & Findings & Sources \\
\hline \multirow[t]{12}{*}{ Buttons } & Preference for larger keypad buttons & $\begin{array}{l}\text { Bruder, Blessing, \& Wandke (2007); Caprani et al. (2012); Hassan } \\
\text { \& Nasir (2008); Irie et al. (2005); Kim et al. (2007); Kurniawan } \\
\text { (2008); Mann et al. (2004); Olwal, Lachanas, \& Zacharouli (2011) }\end{array}$ \\
\hline & Favor raised buttons that offer accurate dialing and text writing, & Zhou et al. (2012); Hassan \& Nasir (2008); Kim et al. (2007); \\
\hline & providing tactile feedback when pressed & Olwal et al. (2011); Pattison \& Stedmon (2006); Sulaiman \& \\
\hline & & Sohaimi (2010); Wang (2008) \\
\hline & Feedback should be immediate, visual, auditory, and/or tactile & Al-Razgan et al. (2012); Harada et al. (2013); Kim et al. (2007); \\
\hline & & Olwal et al. (2011); Waloszek (2010) \\
\hline & The arrangement of buttons (e.g., enough space between buttons; the & Al-Razgan et al. (2012); Olwal et al. (2011); Abdul Razak, Razak, \\
\hline & keypad placed at the bottom of the interface) & Wan Adnan, \& Ahmad (2013); Lorenz \& Oppermann (2009) \\
\hline & The buttons must be easy to understand and distinguish from one & Bruder et al. (2007); Caprani et al. (2012); Hassan \& Nasir (2008); \\
\hline & another either visually or by touch & Irie et al. (2005) \\
\hline & Scroll buttons should be avoided, minimized in number, or placed on & Abdul Razak et al. (2013); Boustani (2010); Caprani et al. (2012); \\
\hline & the side of the phone & Gao et al. (2015); Olwal et al. (2011) \\
\hline
\end{tabular}


Table 1. Continued...

\begin{tabular}{|c|c|c|}
\hline Interaction elements & Findings & Sources \\
\hline \multirow[t]{2}{*}{ Display } & High contrasts, options to zoom in and increase the font size are desired & $\begin{array}{l}\text { Bruder et al. (2007); Caprani et al. (2012); Hasegawa, Omori, } \\
\text { Matsunuma, \& Miyao (2006); Irie et al. (2005); Kim et al. } \\
\text { (2007); Kurniawan (2008); Mann et al. (2004); Massimi } \\
\text { (2007); Olwal et al. (2011); Wang (2008) }\end{array}$ \\
\hline & $\begin{array}{l}\text { Prolonged screen dimming to provide more time for completing } \\
\text { operations }\end{array}$ & Hassan \& Nasir (2008) \\
\hline \multirow[t]{2}{*}{ Graphics } & Simple and meaningful icons without decoration and animation & $\begin{array}{l}\text { Boustani (2010); Lorenz \& Oppermann (2009); Koutsourelakis } \\
\text { \& Chorianopoulos (2010); Leung, Findlater, McGrenere, Graf, } \\
\text { \& Yang (2010) }\end{array}$ \\
\hline & Appropriate/conservative colors with high contrast & Gao et al. (2015); Irie et al. (2005); Waloszek (2010) \\
\hline \multirow[t]{2}{*}{ Form factors } & The device should be big, enable a comfortable grip, and be lightweight & $\begin{array}{l}\text { Hassan \& Nasir (2008); Kim et al. (2007); Kurniawan (2008); } \\
\text { Massimi (2007) }\end{array}$ \\
\hline & $\begin{array}{l}\text { Audio adjustments should be integrated into the device and hearing aids } \\
\text { available }\end{array}$ & Boustani (2010); Caprani et al. (2012); Kim et al. (2007) \\
\hline
\end{tabular}


Table 2. Key findings of studies with older adults related to menu and navigation interaction elements of feature phones

\begin{tabular}{|c|c|c|}
\hline Interaction elements & Findings & Sources \\
\hline Menu & $\begin{array}{l}\text { Menu structure must be simple and flattened; nesting of features } \\
\text { minimized or avoided }\end{array}$ & $\begin{array}{l}\text { Kim et al. (2007); Bay \& Ziefle (2004); Jones \& Marsden (2006); Kurniawan } \\
\text { (2006); Irie et al. (2005); Kause (2013); Kim et al. (2007); Lorenz \& Oppermann } \\
\text { (2009); Zhou et al. (2012); Ziefle, Künzer, \& Bodendieck (2004); Sulaiman \& } \\
\text { Sohaimi (2010) }\end{array}$ \\
\hline Navigation & $\begin{array}{l}\text { Easy-to-use menus should be preferred, as many older adults } \\
\text { experience disorientation with menu navigation }\end{array}$ & $\begin{array}{l}\text { Maguire \& Osman (2003); Armstrong et al. (2010); Hassan \& Nasir (2008); Kim et } \\
\text { al. (2007); Kurniawan (2008); Zhou et al. (2012); Arning \& Ziefle (2007); Parush } \\
\text { \& Yuviler-Gavish (2004); Pattison \& Stedmon (2006); Ziefle \& Bay (2005, 2006) }\end{array}$ \\
\hline & $\begin{array}{l}\text { Small size of a phone's display hinders navigation; the full menu } \\
\text { cannot be shown at one time }\end{array}$ & Zhou et al. (2012); Ziefle \& Bay (2005) \\
\hline Function naming & Functions should be easy to understand and recall & $\begin{array}{l}\text { Chen, Chan, \& Tsang (2013); Hassan \& Nasir (2008); Kim et al. (2007); Ziefle \& } \\
\text { Bay (2005) }\end{array}$ \\
\hline & $\begin{array}{l}\text { Foreign expressions, abbreviations, and technical terms should be } \\
\text { avoided in menus }\end{array}$ & $\begin{array}{l}\text { Holzinger, Searle, Kleinberger, Seffah, \& Javahery (2008); Kim et al. (2007); } \\
\text { Ziefle \& Bay (2005) }\end{array}$ \\
\hline & $\begin{array}{l}\text { Terminology should be simplified, consistent, and self- } \\
\text { explanatory }\end{array}$ & $\begin{array}{l}\text { Kim et al. (2007); Ziefle \& Bay (2006); Abdul Razak et al. (2013); Lorenz \& } \\
\text { Oppermann (2009); Pijukkana \& Sahachaisaeree (2010) }\end{array}$ \\
\hline
\end{tabular}


Table 3. Key findings of studies related to interaction elements addressed in the research on (touchscreen-based) smartphones with older adults

\begin{tabular}{|c|c|c|}
\hline Interaction elements & Findings & Sources \\
\hline Feedback & $\begin{array}{l}\text { Multimodal feedback with auditory and tactile signals enhances } \\
\text { older adults' performance and subjective benefits }\end{array}$ & Hwangbo et al. (2013); Lee et al. (2009) \\
\hline \multirow[t]{3}{*}{ Target size and position } & $\begin{array}{l}\text { Pointing performance is increased with larger targets and wider } \\
\text { spacing between them }\end{array}$ & Hwangbo et al. (2013); Zhou et al. (2012) \\
\hline & $\begin{array}{l}\text { Pointing performance improves with the targets located in the } \\
\text { upper right direction from the screen center point }\end{array}$ & Hwangbo et al. (2013) \\
\hline & Optimal target size is between $14 \mathrm{~mm}$ and $17.5 \mathrm{~mm}$ & Leitao \& Silva (2012) \\
\hline \multirow[t]{4}{*}{ Gestures } & $\begin{array}{l}\text { Older adults have difficulty in recognizing when a button or target } \\
\text { is pressed, which often leads to long taps and pressing of wrong } \\
\text { buttons }\end{array}$ & Furuki \& Kikuchi (2013); Harada et al. (2013); Motti et al. (2013) \\
\hline & Problems with text entry using virtual keyboards & Motti et al. (2013); Zhou et al. (2014a); Zhou et al. (2012) \\
\hline & $\begin{array}{l}\text { Additional time needed to comprehend and learn the movements } \\
\text { needed for touchscreen gestures }\end{array}$ & Furuki \& Kikuchi (2013); Motti et al. (2013); Zhou et al. (2014a) \\
\hline & Difficulties in identifying tappable areas on touchscreens & Harada et al. (2013); Zhou et al. (2012) \\
\hline
\end{tabular}


Table 4. The descriptive characteristics of the analyzed design guidelines and checklists

\begin{tabular}{|c|c|c|c|c|c|c|c|c|c|}
\hline \# & Author(s) & Year & Type & Device $^{\mathrm{a}}$ & Empirical validation $^{\mathrm{b}}$ & Items & Orig. dimensions ${ }^{\mathrm{c}}$ & Categories & Dimensions \\
\hline 1 & Pattison and Stedmon & 2006 & Design guidelines & Feature phone & No & 10 & 4 & 8 & 4 \\
\hline 2 & Massimi et al. & 2007 & Design guidelines & Feature phone & No & 12 & - & 8 & 5 \\
\hline $3 *$ & Van Biljon et al. & 2010 & Checklist & Feature phone & - & - & - & - & - \\
\hline 4 & Al-Razgan et al. & 2012 & Design guidelines & Touchscreen phone & No & 17 & 3 & 20 & 4 \\
\hline 5 & Van Dyk et al. & 2013 & Checklist & Feature phone & No & 54 & 3 & 24 & 7 \\
\hline 6 & Calak & 2013 & Checklist & Smartphone & Yes & 19 & 5 & 14 & 4 \\
\hline 7 & Díaz-Bossini and Moreno & 2014 & Design guidelines & Smartphone & Yes & 19 & 6 & 10 & 6 \\
\hline 8 & Silva et al. & 2014 & Checklist & Smartphone & Yes & 35 & 6 & 17 & 7 \\
\hline \multirow[t]{2}{*}{9} & Mi et al. & 2014 & Checklist & Smartphone & Yes & 44 & 6 & 25 & 7 \\
\hline & Mean (Standard deviation) & & & & & $26.3(15.1)$ & $4.7(1.3)$ & $15.8(6.4)$ & $5.5(1.3)$ \\
\hline
\end{tabular}

Note: *The checklist developed by Van Biljon et al. (2010) was excluded from further analysis as the checklist by Van Dyk et al. (2013) represented its extended version.

a Because the checklist of Van Dyk et al. (2013) includes only one item related to touchscreen phones it also represents an extension of the feature phone checklist of Van

Biljon et al. (2010) and was thus associated with feature phones. ${ }^{\mathrm{b}}$ The presence of empirical validation was assessed based on the information and/or reference provided in the original study where the design guidelines and checklists were presented. ${ }^{\mathrm{c}}$ The number of dimensions originally defined by the author(s) of the design guideline/checklist. 
Table 5. Average number of categories and dimensions of design guidelines and checklists by year of publication and type of device

\begin{tabular}{llll}
\hline & & & \multicolumn{2}{c}{ Mean } \\
Variable & Value & Categories $^{\mathrm{a}}$ & Dimensions $^{\mathrm{b}}$ \\
\hline Year & 2006 & 8 & 4 \\
& 2007 & 8 & 5 \\
& 2012 & 20 & 4 \\
& 2013 & 19 & 5.5 \\
& 2014 & 17.4 & 6.7 \\
Type of device & Feature phone $(\mathrm{F})^{\mathrm{c}}$ & 13.3 & 5.3 \\
& Smartphone or Touchscreen phone $(\mathrm{S})^{\mathrm{d}}$ & 17.2 & 5.6 \\
& & 15.8 & 5.5 \\
\hline
\end{tabular}

Note: ${ }^{\mathrm{a}} r_{s}=0.710 .{ }^{\mathrm{b}} r_{s}=0.543 .{ }^{\mathrm{c}} D=F-S=-3.9 .{ }^{\mathrm{d}} D=-0.3$. 
Table 6. Usability dimensions and categories for the design of mobile phones for older adults

\begin{tabular}{|c|c|c|c|c|c|}
\hline Dimension & Category & $\mathrm{N}^{\mathrm{b}}$ & Dimension & Category & $\mathrm{N}^{\mathrm{b}}$ \\
\hline \multirow[t]{6}{*}{ Screen (SC) } & Display size & 3 & Text (TX) & Ease of text entry & 1 \\
\hline & High contrast & 7 & & Font size & 5 \\
\hline & Colors & 4 & & Font type & 2 \\
\hline & High resolution & 0 & Menu (ME) & Simple menu & 4 \\
\hline & Slower dimming & 2 & & Consistent menu & 4 \\
\hline & Zooming and magnification & 3 & & Minimized nesting & 2 \\
\hline \multirow[t]{5}{*}{ Touchscreen (TS) ${ }^{\mathrm{a}}$} & Touchscreen gestures & 2 & & Ease of navigation & 5 \\
\hline & Feedback & 3 & & Current location in the menu & 2 \\
\hline & Target/Icon properties & 2 & Exterior $(\mathrm{EX})$ & Device size & 5 \\
\hline & Content layout & 4 & & Shape & 5 \\
\hline & Animation & 1 & & Material & 4 \\
\hline \multirow[t]{8}{*}{ Keypad (KP) } & Button type & 5 & & Battery charging & 4 \\
\hline & Button shape & 4 & & External volume buttons & 4 \\
\hline & Button size & 5 & & Hearing aid compatible & 2 \\
\hline & Button feedback & 3 & Content (CO) & Terminology & 4 \\
\hline & Button responsiveness & 5 & & Function labels & 1 \\
\hline & Labeled buttons & 4 & & Additional languages & 2 \\
\hline & Button positioning & 5 & & User help and/or manual & 2 \\
\hline & Number of buttons & 4 & & Error messages & 3 \\
\hline
\end{tabular}

Note: ${ }^{a}$ With the exception of the touchscreen, all dimensions were applied to all design guidelines and checklists that addressed both feature phones and smartphones (see Table 3). ${ }^{\mathrm{b}} \mathrm{N}$ indicates the number of guidelines and checklists that include the selected category. 
Table 7. Average proportion of categories in dimensions of design guidelines and checklists by year of publication and type of device

\begin{tabular}{|c|c|c|c|c|c|c|c|c|}
\hline Variable & Value & $\mathrm{SC}^{\mathrm{b}}$ & TS & $\mathrm{KP}$ & TX & $\mathrm{ME}$ & EX & $\mathrm{CO}$ \\
\hline \multirow[t]{6}{*}{ Year } & 2006 & 16.7 & 0 & 37.5 & 0 & 40 & 33.3 & 0 \\
\hline & 2007 & 0 & 0 & 37.5 & 33.3 & 20 & 16.7 & 40 \\
\hline & 2012 & 83.3 & 0 & 100 & 33.3 & 0 & 100 & 0 \\
\hline & 2013 & 41.7 & 30 & 68.8 & 16.7 & 70 & 66.7 & 30 \\
\hline & 2014 & 38.9 & 60 & 41.7 & 55.6 & 46.7 & 38.9 & 46.7 \\
\hline & $r_{s}$ & 0.373 & 0.823 & -0.158 & 0.676 & 0.381 & 0.037 & 0.552 \\
\hline Type of & Feature phone $(\mathrm{F})$ & & & & & & & \\
\hline \multirow[t]{5}{*}{ device } & & 16.7 & 20.0 & 58.3 & 22.2 & 53.3 & 27.8 & 33.3 \\
\hline & Smartphone & & & & & & & \\
\hline & Touchscreen phone (S) & 50.0 & 36.0 & 52.5 & 40.0 & 36.0 & 63.3 & 28.0 \\
\hline & ${ }^{\mathrm{a}} \mathrm{D}=\mathrm{F}-\mathrm{S}$ & & & & & & & \\
\hline & & -33.3 & -16.0 & 5.8 & -17.8 & 17.3 & -35.6 & -5.3 \\
\hline Total & & 37.5 & 30.0 & 54.7 & 33.3 & 42.5 & 50.0 & 30.0 \\
\hline
\end{tabular}

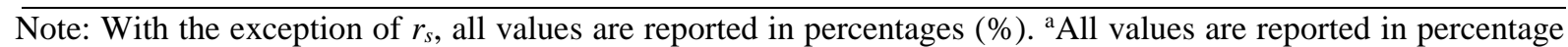
points. ${ }^{\mathrm{b}} \mathrm{SC}-$ Screen, TS - Touchscreen, KP - Keypad, TX - Text, ME - Menu, EX - Exterior, CO - Content. 
Figures

Figure 1. Study design with four stages

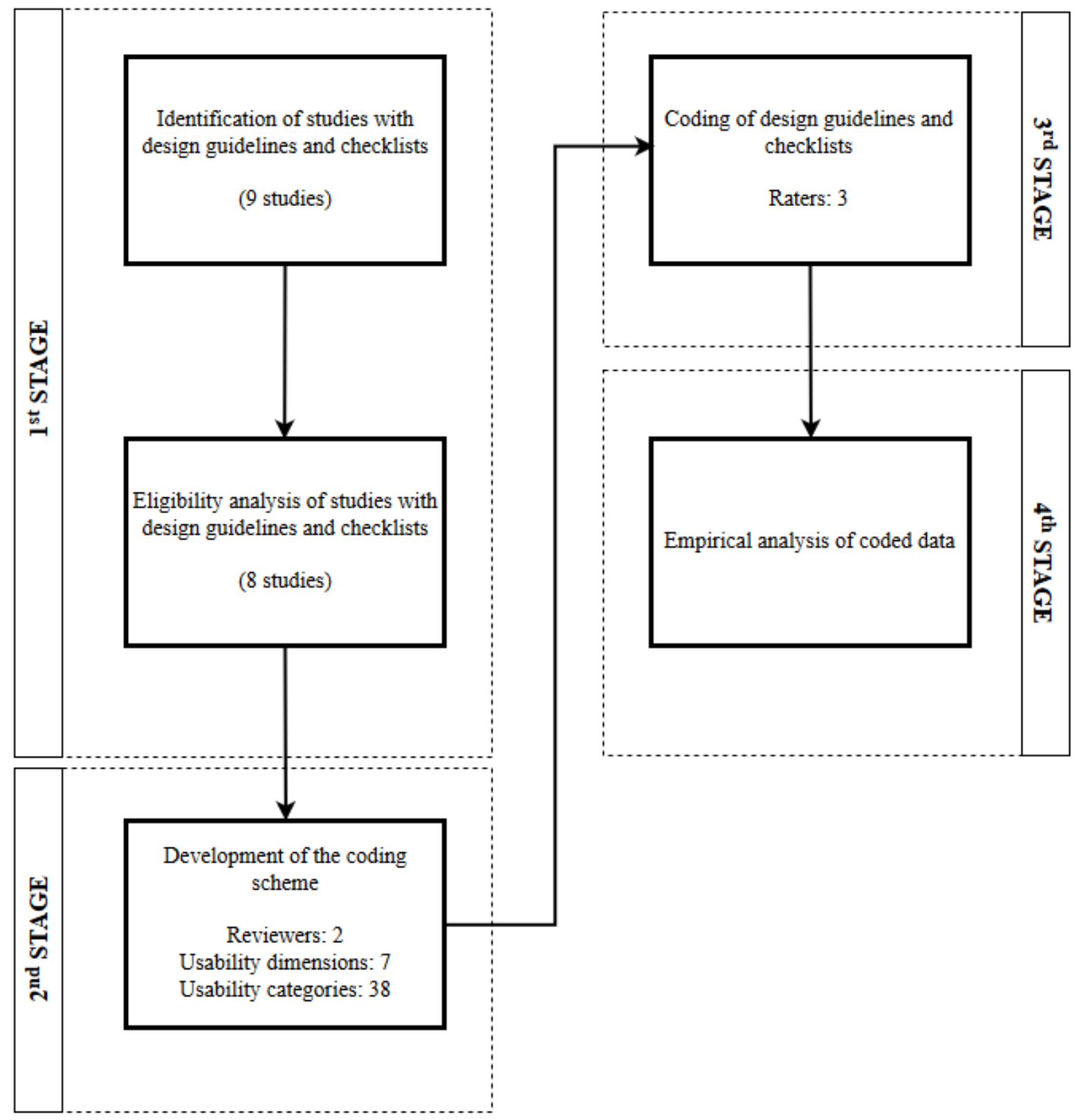




\section{Additional author information}

Andraž Petrovčič, Ph.D., is an Assistant Professor and a Research Fellow at the Centre for Social Informatics in the Faculty of Social Sciences at University of Ljubljana, Slovenia. His research interests include mobile usability, age-friendly interaction design, and sociotechnical aspects of older adults' interactions with new technologies for independent living at home.

Sakari Taipale, Ph.D., works as an Academy of Finland Research Fellow in the Department of Social Sciences and Philosophy at the University of Jyvaskyla, Finland. His current research projects relate to the use of mobile communication and the internet across the life course and between generations.

Ajda Rogelj, M.A., received a Masters in Social Informatics from University of Ljubljana. Currently she works as a research methods expert at the National Institute of Public Health of the Republic of Slovenia and is an active member of its core research team. Her interests include micro and macro implementation of e-health and e-care services.

Vesna Dolničar, Ph.D., is an Assistant Professor of Social Informatics in the Faculty of Social Sciences, University of Ljubljana, Slovenia. She has been involved in more than 20 (inter)national research projects (e.g. FP6, Interreg, COST Actions, LLP, Erasmus+, EC tenders) related to the fields of digital inequalities and acceptability of e-care and e-health solutions. 